\title{
Sesli ve Sessiz Okumada Göz Hareketleri: Bir Göz İzleme (Eye Tracking) Çalışması*
}

\author{
Muhammet BAŞTUĞ, Kağan KESKiN, İrfan şiMŞEK**
}

Sesli ve Sessiz Okumada Göz Hareketleri: Bir Göz İzleme (Eye Tracking) Çalışması

Özet

Bu araştırma, okuyucuların sesli ve sessiz okuma sırasındaki göz hareketlerini incelemek amacıyla yürütülmüştür. Çalışmaya Eğitim Fakültesi 3. ve 4. Sınıfta öğrenim gören toplam 48 öğretmen adayı katılmıştır. Katılımcılara SMI Marka Göz Takip Cihazı kullanılarak ekran üzerinden okuma yaptırılmıştır. Okumalara ilişkin Cihaz üzerinden tutulan kayıtlardan, okuyucuların sesli ve sessiz okumadaki göz hareketlerine ilişkin analizler yapılmıştır. Buna göre, göz kırpma sayısı ve süresi sesli okumada sessiz okumaya göre daha yüksek çıkmasına rağmen aradaki fark anlamlı değildir. Diğer taraftan, duraksama sayısı ve duraksama süre ortalaması sesli okumada, sessiz okumaya göre anlamlı derecede farklılaşmıştır. Sıçrama genişliği ortalaması, sıçrama süresi ve sıçrama gecikme ortalaması ise anlamlı farklılaşmamıştır. Gezinti Yolları Mesafesi ise sesli okumada anlamlı derecede yüksek çıkmıştır.

Anahtar Kelimeler: Okuma, Göz hareketleri, Sesli ve sessiz okuma.

\section{Giriş}

Okuma, yazı ile birlikte, insanları diğer canlılardan ayıran, ancak psikologların ve bilişsel bilim adamlarının laboratuvarlarında en çok incelenen bilişsel becerilerden biridir (Wallot, 2011). Okuma

\footnotetext{
*Bu çalışma16. Uluslararası Sını Öğretmenliği Eğitimi Sempozyumu'nda sözlü bildiri olarak sunulmuştur.

** Muhammet BAŞTUĞ, Doç..Dr., İstanbul Üniversitesi - Cerrahpaşa, Hasan Ali Yücel Eğitim Fakültesi, mbastug@istanbul.edu.tr; ORCID ID orcid.org / 0000-0002-5949-6966, Kağan KESKIN, Doç.Dr., Düzce Üniversitesi Eğitim Fakültesi, kagankeskin@duzce.edu.tr; ORCID ID orcid.org / 0000-0002-5495-1747, İrfan ŞiMŞEK, Dr.Öğr.Üyesi, İstanbul Üniversitesi - Cerrahpaşa, Hasan Ali Yücel Eğitim Fakültesi, irfan@istanbul.edu.tr; ORCID ID orcid.org / 00000002-7481-5830
} 
beyinde gerçekleşen, anlam kurmaya dayalı karmaşık bir düşünme sürecidir. Bu süreçte değerlendirme, muhakeme etme, problem çözme, hayal etme gibi öğeler yer almaktadır (Akyol, 2015). Okuma, bir etkileşim sürecidir. Okuyucu ve metin arasında amaçlı ve düşünceye dayalı etkileşim gerektiren bir süreçtir (Panel (US), Health ve Development (US), 2000). Okuyucu metinle karşılaştığında bir taraftan kelimeyi tanımaya ve ayırt etmeye; diğer taraftan ön bilgilerini ve strateji bilgisini kullanarak metni anlamaya çalışır. Bu tanımlardan hareketle okuma, fiziksel ve zihinsel süreçleri içeren, okuyucu ve metin (yazar) arasındaki etkileşimi gerektiren, anlama amacını taşıyan, aktif bir etkinliktir.

Okuma literatürü giderek genişlemiş ve özellikle son yıllarda teknolojinin gelişmesi ile birlikte her alanda olduğu gibi okuma alanında da daha ayrıntılı verilerin üretilmesine başlanmıştır. Örneğin, okurken göz hareketlerinin yüksek bir doğrulukla takip edilmesi, teknolojinin bu alana kattığı önemli bir kazanımdır. Günümüzde dikkat çekici bir çalışma alanı olan göz hareketleri ve göz hareketlerinin okumanın farklı değişkenleriyle olan ilişkisi araştırmacıların ilgi odağı haline gelmiştir. Bütün bu araştırmalarda göz izleme teknolojisi kullanılmaktadır. Göz izleme, basit olarak tanımlamak gerekirse, başın pozisyonuna göre göz hareketini ölçme sürecidir. Göz hareketlerini ölçmek için tasarlanan cihaz bir göz izleme teknolojisi olarak düşünülebilir (Vadivel, 2014). Göz izleme teknolojisi ve araçları, psikoloji, bilişsel dilbilim ve ürün tasarımında yoğun şekilde kullanılmaktadır. Nelson (2010) okuma eyleminin altında yatan bilişsel süreçleri anlamak için göz izleme teknolojisini kullanmanın gerekliliğine vurgu yapmaktadır. Hatta göz hareketlerinin geçerliği, bilişsel işleme ve göz hareketleri arasındaki ilişkiye yani göz-düşünce bağlantısına dayandırılmaktadır (Schooler, 2004). Bununla birlikte okuma sürecinde metin etkisi, söz varlığı faktörü ve bireysel okuyucu farklılıklarını ortaya koymada göz izlemeden yararlanılabilir.

Okuma sürecinde göz izleme teknolojisi kullanımı, okuma çalışmalarında, doğrudan veri elde edilmesine ve yorumlanmasına fırsat vermektedir. Bu yönüyle, okuma becerisinin işleyişi ve niteliği hakkında daha ayrıntılı bilgi edinme şansı doğmaktadır (Nelson, 2010). Günümüzde göz hareketleri ve okumayla ilgili faktörlerin ilişkisine ilişkin farklı çalışmalar yapıımıştır. Bazı çalışmalarda (Ashby, 2006; Ashby ve Clifton Jr, 2005) sessiz okuma sırasında prozodi araştırımıştır. Ashby, Yang, Evans ve Rayner (2012) çalışmasında sesli ve sessiz okumada algısal mesafeyi; Ashby, Treiman, Kessler ve Rayner (2006) sessiz okuma sırasında, sesli harfleri işleme süreçlerini; Altarriba, Kroll, Sholl ve Rayner (1996) sözlü ve kavramsal sınırlamaların, karışık dil cümlelerini okumaya etkisini göz izleme yoluyla araştırmışlardır. Folk ve Morris (1995) çalışmasında ise göz izlemeyle, sesli okuma sürecinde çoklu leksikal kodları incelemiştir. Krieber vd. (2017) çalışmasında sesli ve sessiz okumada mekânsal ve zamanla ilgili göz hareketi değişkenlerini belirlemeyi amaçlamıştır. Ülkemizde yapılan okumaya yönelik çalışmalarda ise eğik yazı, düz yazı anlamlı ve anlamsız metinler Karaman, Çeliker, Karaman ve Üstün (2016) gazete okuma davranışında sayfa tasarımının okumanın yönlendiriciliği üzerindeki etkisi (Onursoy, Kilıç ve Er, 2010) gibi konular çalışılmıştır.

Literatüre bakıldığında okuma sürecinde göz izleme teknolojisinin kullanımına ilişkin çok sayıda araştırma yapılmıştır. Özellikle Rayner'in (2009) çalışmaları bu alanda oldukça zengindir. Ancak 
yapılan bu çalışmaların çoğunluğu sessiz okumaya ilişkindir. Oysa okuma sürecinde konuşma dilinin özelliklerinin sergilendiği sesli okuma, günümüzde önemli görülmekte ve göz izleme çalışmalarında dikkat gerektirmektedir (Solomon, 2009). Diğer taraftan sesli okuma sürecindeki sorunlar, genel okuma gelişimindeki sorunlarla birlikte düşünülmektedir. Bundan dolayı, sesli okumada göz izleme çalışmalarının artması, sesli okuma gelişimine ilişkin daha derinlemesine bilgi edinme açısından gereklilik olarak görülmektedir. Bu konudaki sınılı sayıdaki araştırmalardan biri olan Solomon'un (2009) çalışması sesli ve sessiz okuma sürecinde göz hareketlerine ilişkin önemlidir. Araştırmada iki farklı deney yapılmıştır. Birincisinde metin sessiz okunmuş, ikincisinde yüksek sesle okunmuştur. Solomon araştırmasında, yüksek sesle okurken bilgi kullanımının zaman seyrinin değişip değişmediğini ve eğer bir değişim varsa bu değişimin nasıl olduğunu incelemeye çalışmıştır. Ancak özellikle sesli ve sessiz okumanın doğrudan karşılaştıııldığı çalışmalar oldukça yetersizdir. Bu durum sesli ve sessiz okumaya ilişkin teorik ve pratik bakışı geliştirmek açısından önemlidir.

Sesli ve sessiz okuma gerek süreç gerekse üretim bakımından farklılaşmaktadır. Sesli okumada okuma sürecine ses organları hatta işitme de dâhil olmaktadır. Okuyucu, sesli okumayı ses organları ve konuşma dilinin özelliklerini de kullanarak yapmakta, bu süreçte okuyucu kendi sesli okumasını işitmekte ve okumasını sürdürmektedir. Sessiz okumada ise ses organları ve işitme, okuma sürecine dâhil olmamaktadır. Sesli ve sessiz okumadaki süreçsel farklııklar gibi özellikle okumanın hız ve anlama öğeleri olarak, okumanın üretim boyutunda da farklı sonuçlar vermektedir. Kaynaklara göre sesli okuma hızı, sessiz okumaya göre daha düşüktür. Bu düşüklüğün nedeni, sesli okuma sırasında ses organlarının işe girmesi ve sesletim sırasındaki zaman kaybına bağlanmaktadır. Dilin seslendirme süresinin, gözün görme ve algılama süresinden daha fazla olması, sesli okuma hızını düşürmektedir (Ünalan, 2006). Bununla birlikte sesli okuma sürecinde anlama ikinci plana atılmakta ve sessiz okumaya göre okunan metinden anlam çıkarma daha düşük olmaktadır (Çiftçi, 2001). Ancak özellikle okuma türü olarak sesli ve sessiz okumada göz hareketlerinin durumunun ne olduğu yeterince bilinmemektedir. Yapılan çalışmalar, sessiz okumanın sesli okumaya göre hız ve anlama açısından daha iyi sonuçlar verdiğini ortaya koysa da göz hareketlerinin bu süreçteki rolünü de dikkate almak bir zorunluluktur. Okumanın çıktı aşamasındaki farklılaşmada göz hareketlerinin, odaklanma genişliği ve süresinin rolünün ne olduğu yeterince açık değildir. Bu bağlamda yapılan araştırmayla sesli ve sessiz okuma sırasında göz hareketlerini izlemek amaçlanmıştır. Çalışma sonuçlarının sesli ve sessiz okuma süreçlerini teorik olarak anlamaya katkı sağlaması beklemektedir.

\section{Yöntem}

Araştırma betimsel desende tasarlanmış, mevcut durumun ne olduğunu tespit etmeye intiyaç duyulduğundan tarama yönetimi kullanılmıştır. Betimsel desen, var olan bir durum veya olayı nicel ya da nitel yönden belirleyen bir araştırma türüdür (Creswell, 2017). Betimsel araştırmalar; olay, durum, grup, kurum vb. alanların ne olduğunu anlamaya, betimlemeye ve açıklamaya çalışır (Gay ve Mills, 2015; McMillan ve Schumacher, 2014). 
Muhammet BAŞTUĞ | Kağan KESKIN | İrfan ŞiMŞEK

\section{1. Çalışma Grubu}

Çalışmaya Eğitim Fakültesi 3. ve 4. sınıfta öğrenim gören toplam 48 öğretmen adayı katılmıştır.

\begin{tabular}{lccc}
\hline \hline Bölüm & KIz & Erkek & Toplam \\
\hline Bilgisayar ve Öğretim Teknolojileri Öğretmenliği & 9 & 14 & 23 \\
Sınıf Öğretmenliği & 4 & 18 & 22 \\
Ingilizce Öğretmenliği & 0 & 3 & 3 \\
Toplam & 13 & 35 & 48 \\
\hline
\end{tabular}

\section{2. İşlem}

- Stil kavramının eğitimsel olarak anlatıldığı 472 kelimelik bilgilendirici türde yazılmış bir metin seçilmiştir. Seçilen metin sesli ve sessiz okuma yapılmak üzere iki eş parçaya ayrılmıştır.

- Katılımcılara önce sesli, daha sonra sessiz okuma yaptırılmıştır.

- $\quad$ SMI Marka Göz Takip Cihazı kullanılarak ekran üzerinden okuma yaptııılmıştır.

- Her katılımcı tek tek test edilmiştir. Göz hareketleri SMI marka göz takip cihazı kullanılarak kaydedilmiştir.

- Seçilen metin ekrandan okuma yaptırılmıştır.

- Krtik cümelerin tek bir satırda olmasına dikkat edilmiş, 14 punda Avenir Next fontu kullanılmıştır.

- Metin parçalanırken anlam bütünlüğünün bozulmamasına, cümlenin parçalanmamasına dikkat edilmiştir.

- Katılımcılar okumanın yapıldığı salona tek tek alınmıştır. Kendisinden önce okuyanı duymamıştır.

\subsection{Verilerin Toplama ve Analiz}

\section{Ekran kaydı:}

Katılımcıların sesli ve sessiz okumaları yaptığı andaki işlemler kayıt altına alınmıştır.

\section{Göz hareketi kaydı:}

Katılımcıların, sesli ve sessiz okuma yaparken göz hareketleri izlenerek kayıt altına alınmıştır. 


\section{Uygulama Öncesi}

Gönüllü olan öğretmen adayları uygulama odasına yerleştirilecek, hem ortama alışmaları sağlanmış hem de araştırma ile ilgili etik kuralların yerine getirilmesi için izin belgesini doldurmaları istenmiştir. Daha sonra araştırmanın kapsamı ve araştırmacının yapacağı işlemler öğretmen adayına aktarılmıştır. Bu bilgiler doğrultusunda araştırma kapsamında tek seferde metnin bir bölümünü sesli, diğer bölümünün ise sessiz okuması gerektiği şeklinde açıklama yapıımıştır.

\section{Uygulama Başlatılırken}

Uygulama başlatılırken, göz hareketlerinin izlenebilmesi ve kayıt altına alınabilmesi için SMI Experiment 2.4 programı ile göz kalibrasyonu yapılmıştır.

\section{Uygulama Esnasında}

SMI Experiment 2.4 programı ile göz kalibrasyonu yapılan katılımcıya, kalibrasyondan sonra gelen ilk metnin sesli, daha sonraki metnin ise sessiz okuması bildirilmiştir. Göz kalibrasyonu takibi yapılarak gerekli görülen durumlarda katılımcı ikaz edilmiştir.

\section{Verilerin Çözümlenmesi/ Yorumlanması}

SMI Experiment 2.4 program ile kaydedilmiş fare ve göz hareketlerini gösteren ekran kayıtları incelenmiştir.

SMI Experiment 2.4 programı ile kayıt altına alınmış olan göz hareketleri, Be Gaze 2.4 progra$\mathrm{m}$ ile analiz edilmiştir. Analizde,

- Bütünde Odaklanma Sayısı (Fixation),

- Gözün Odaklanma Sayısı

- Kılavuzlanmış ilgi Alanlarında Bakış Sırası (Sequence),

- Isı Haritası (Heatmap),

- Gözün Tarama Yolu (Scan Path), değerlerine bakılmıştır.

- Sıçrama sayısı

- Sıçrama süreleri

- Duraksama sayısı

- Duraksama süreleri

- Toplam zaman

- Gezinti yolları

- $\quad$ Sesli ve sessiz okuma süreleri grafik. 


\section{Bulgular}

Sesli ve sessiz okuma göz kırpma ortalama puanları arasındaki farkın anlamlılığı için yapılan ttesti sonuçları Tablo 1'de verilmiştir.

Tablo 1. Göz Kırpma (Blink) Sonuçları Bağımlı T-Testi Tablosu

\begin{tabular}{lllllll}
\hline \hline & Mean & $N$ & Std. Deviation & $t$ & $d f$ & $p$ \\
\hline Göz Kırpma Sayısı (Sesli) & 13,42 & 48 & 11,762 & & & \\
Göz Kırpma Sayısı (Sessiz) & 6,02 & 48 & 5,417 & 6,228 & 47 &, $000^{*}$ \\
Göz Kırpma Süre Ortalaması (Sesli) & 8662,75 & 48 & 28366,704 & & & \\
Göz Kırpma Süre Ortalaması (Sessiz) & 9759,75 & 48 & 30701,419 &,- 849 & 47 &, 400 \\
\hline
\end{tabular}

$* p<.05$

Sesli ve sessiz okumada sgöz kırpma sayıları arasında anlamlı bir fark olduğu gözlenmiştir [t(47) $=6,228, p<.01]$. Sesli okuma puanlarının ortalaması $\bar{X}=13,42$ iken sessiz okuma puanı $\bar{X}=6,02$ dir. Sesli okuma yaparken daha fazla göz kırpması olduğu görülmektedir. Bunun yanında sesli ve sessiz okumada göz kırpma süreleri arasında anlamlı bir fark bulunmamıştır.

Tablo 2. Duraksama (Fixation) Sonuçları Bağımlı T-Testi Tablosu

\begin{tabular}{llllll}
\hline \hline & Mean & $N$ Std. Deviation & $t$ & $d f$ & $p$ \\
\hline Duraksama Sayısı (Sesli) & 275,56 & 4894,471 & & & \\
Duraksama Sayısı (Sessiz) & 198,88 & 4859,607 & 8,212 & 47 &, $000^{*}$ \\
Duraksama Dağılım Ortalaması (Sesli) & 826,71 & 48106,228 & & & \\
Duraksama Dağılım Ortalaması (Sessiz) & 828,25 & 4874,958 &,- 200 & 47 &, 842 \\
Duraksama Süre Ortalaması (Sesli) & 3544,02 & 481557,986 & & & \\
Duraksama Süre Ortalaması (Sessiz) & 2909,90 & 481073,938 & 5,637 & 47 &, $000^{*}$ \\
\hline
\end{tabular}

* $\mathrm{p}<.05$

Sesli ve sessiz okumada duraksama sayıları arasında anlamlı bir fark olduğu gözlenmiştir [t(47) $=8,212, p<.01]$. Sesli okuma puanlarının ortalaması $\bar{X}=275,56$ iken sessiz okuma puanı $\bar{X}=198,88$ dir. Sesli okuma yaparken duraksamanın daha fazla olduğu görülmektedir. Bunun yanında sesli ve sessiz okumada duraksama dağılım ortalamasında arasında anlamlı bir fark bulunmazken, süre ortalamasında anlamlı bir fark görülmektedir $[\mathrm{t}(47)=5,637, \mathrm{p}<.01]$. 
Tablo 3. Sıçrama (Saccade) Sonuçları Bağımlı t-Testi Tablosu

\begin{tabular}{lllllc}
\hline & Mean & N Std. Deviation & $t$ & $d f$ & $p$ \\
\hline Sıçrama Genişliği Ortalaması (Sesli) & 112,10 & 48268,847 & & & \\
Sıçrama Genişliği Ortalaması (Sessiz) & 73,69 & 48189,909 & 2,112 & 47 &, $040 *$ \\
Sıçrama Sayısı (Sesli) & 279,21 & 48100,100 & & & \\
Sıçrama Sayısı (Sessiz) & 200,38 & 4862,853 & 8,099 & 47 &, $000^{*}$ \\
Sıçrama Süresi (Sesli) & 678,17 & 481464,277 & & & \\
Sıçrama Süresi (Sessiz) & 487,10 & 48936,087 & 1,890 & 47 &, 065 \\
Sıçrama Gecikme Ortalaması (Sesli) & 21405,96 & 48113436,325 & & & \\
Sıçrama Gecikme Ortalaması (Sessiz) & 3579,92 & 482121,997 & 1,084 & 47 &, 284 \\
Sıçrama Hızı Ortalaması (Sesli) & 985,15 & 48747,099 & & & \\
Sıçrama Hızı Ortalaması (Ses) & 776,13 & 48268,261 & 1,810 & 47 & , 077
\end{tabular}

$* p<.05$

Sesli ve sessiz okumada sıçrama sayıları arasında anlamlı bir fark olduğu gözlenmiştir [t(47) = 2,112, p<.05]. Sesli okuma puanlarının ortalaması $\bar{X}=112,10$ iken sessiz okuma puanı $\bar{X}=73,69$ dir. Sesli okuma yaparken sıçramanın sessiz okumaya göre daha fazla olduğu görülmektedir. Bunun yanında sesli ve sessiz okumada sıçrama süresi dağılım ortalamasında arasında anlamlı bir fark bulunmazken, sıçrama süresinde anlamlı bir fark görülmektedir $[t(47)=8,099, p<.01]$.

Tablo 4. Gezinti Yolları (Scan Path) Sonuçları Bağımlı t-Testi Tablosu

\begin{tabular}{lllllll}
\hline \hline & Mean & $N$ & Std. Deviation & $t$ & $d f$ & $p$ \\
\hline Gezinti Yolları Mesafesi (Sesli) & 30860,96 & 48 & 8063,198 & & & \\
\hline Gezinti Yolları Mesafesi (Sessiz) & 25119,25 & 48 & 5548,813 & & & \\
\hline
\end{tabular}

$* \mathrm{p}<.05$

Sesli ve sessiz okumada gezinti yolları mesafesi arasında anlamlı bir fark olduğu gözlenmiştir $[\mathrm{t}(47)=7,825, \mathrm{p}<.01]$. Sesli okuma puanlarının ortalaması $\bar{X}=30860,96$ iken sessiz okuma puanı $\bar{X}=25119,25$ dir. 
Sesli ve sessiz okuma sürecindeki ısı haritası (Heat Map) aşağıda verilmiştir.

Sessiz Okuma Isı Haritası

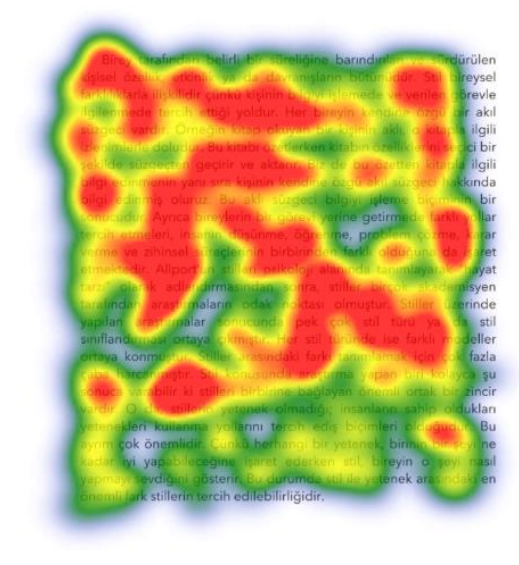

Sesli Okuma Isı Haritası

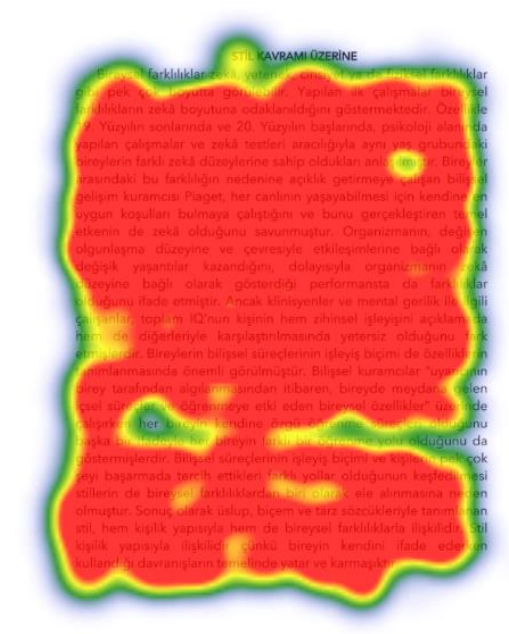

\section{Tartışma ve Sonuç}

Göz kırpma sayısı okuma türüne göre sesli okumada anlamlı derecede daha yüksek çıkmıştır. Buna göre okuyucular sesli okuma sırasında, sessiz okumaya göre daha fazla göz kırpma davranışı göstermektedir. Göz kırpma süre ortalamaları okuma türüne göre anlamlı farklılaşmamıştır. Ancak anlamlı olmasa da sessiz okuma sırasında bu süre ortalaması, sesli okumaya göre daha yüksek çıkmıştır. Duraksama sayısı ve duraksama süre ortalaması sesli okumada anlamlı derecede daha yüksek çıkmıştır. Duraksama dağılım ortalaması ise her iki okuma türünde de benzer ortalamada çıkmıştır. Sıçrama genişliği ortalaması ve sıçrama sayısı sesli okumada anlamlı derecede daha yüksek çıkmıştır. Sıçrama hızı ortalaması, sıçrama süresi ve sıçrama gecikme ortalaması ise anlamlı farklılaşmamıştır. Gezinti Yolları Mesafesi ise sesli okumada anlamlı derecede yüksek çıkmıştır. Bu sonuçlara toplu bakıldığında Krieber vd. (2017) çalışmasıyla büyük oranda örtüşmektedir. Krieber vd. (2017) çalışmalarında ilk odaklanma süresi, ortalama odaklanma süresi, duraksama süresi, sıçrama sayısı, sesli okumada, sessiz okumaya göre daha fazladır ve bu farklılık istatistiksel olarak anlamlı bulmuştur. Vorstius, Radach ve Lonigan (2014) çalışmalarında okuma süresini belirleyici iki 
temel değişken olarak duraksama sayısı ve duraksama süresinin olduğu vurgulanmıştır. Buna göre sesli okumada, sessiz okumaya göre duraksama sayısı ve süresi daha fazladır. Vorstius vd. (2014) okumadaki göz hareketlerinin değişkenliğini bilişsel yük ile okumadaki dilsel süreçler arasındaki ilişkiyle yorumlamıştır. Rayner (2009) çalışmasında da duraksama süresi ortalaması, sesli okumada, sessiz okumaya göre daha fazladır. Bu sonuçlar özellikle sessiz okumanın sesli okumaya göre daha hızı olmasına ilişkin tartışmalara da farkı bir yorum getirebilir. Çünkü literatürde, sessiz okumanın daha hızı olması, dilin seslendirme süresinin, gözün görme ve algılama süresinden daha fazla olmasına dayandııımaktadır (Ünalan, 2006). Oysa bu araştırmanın sonuçları ve göz hareketlerine ilişkin literatür incelendiğinde, sesli okumada odaklama ve sıçrama süreleri daha fazladır. Dolayısıyla sesli okumadaki zaman kaybının nedenleri arasında, okuma sırasındaki göz hareketleri de olabilir. Bu bakış açısı, farklı tür ve desendeki araştırmalarla incelenebilir.

Öneriler:

- Özellikle okuduğunu anlama ve akıcı okuma performansıyla yordayıcı çalışmalar yapılabilir.

- Farklı sınıf düzeylerinde, özellikle ilk sınıflarda, bu çalışmalar boylamsal olarak yapılabilir.

- Metin türleri ve metnin okunabilirlik durumu araştırılabilir.

- Okuma sürecindeki göz hareketleri ve beyin aktivasyonları arasındaki ilişki araştırılabilir.

\section{Kaynaklar}

Akyol, H. (2015). Türkçe ilk okuma yazma öğretimi (15. bs). Ankara: Pegem Akademi Yayıncılık.

Altarriba, J., Kroll, J. F., Sholl, A., \& Rayner, K. (1996). The influence of lexical and conceptual constraints on reading mixed-language sentences: Evidence from eye fixations and naming times. Memory \& Cognition, 24(4), 477-492.

Ashby, J. (2006). Prosody in skilled silent reading: Evidence from eye movements. Journal of Research in Reading, 29(3), 318-333.

Ashby, J., \& Clifton Jr, C. (2005). The prosodic property of lexical stress affects eye movements during silent reading. Cognition, 96(3), B89-B100.

Ashby, J., Treiman, R., Kessler, B., \& Rayner, K. (2006). Vowel processing during silent reading: Evidence from eye movements. Journal of Experimental Psychology: Learning, Memory, and Cognition, 32(2), 416.

Ashby, J., Yang, J., Evans, K. H., \& Rayner, K. (2012). Eye movements and the perceptual span in silent and oral reading. Attention, Perception, \& Psychophysics, 74(4), 634640. 
Creswell, J. W. (2017). Research design: Qualitative, quantitative, and mixed methods approaches. Sage publications.

Çiftçi, M. (2001). Sesli okuma. Bilge Dergisi, (24), 178-183.

Folk, J. R., \& Morris, R. K. (1995). Multiple lexical codes in reading: Evidence from eye movements, naming time, and oral reading. Journal of Experimental Psychology: Learning, Memory, and Cognition, 21(6), 1412.

Gay, L. R., \& Mills, G. E. (2015). Educational Research: Competencies for Analysis and Applications, Global Edition: Edition 11.

Karaman, G. E., Çeliker, O., Karaman, E., \& Üstün, Ö. (2016). Eğik yazı mı? Düz yazı mı? Göz izleme cihazı ile bir plot çalışma. Yönetim Bilişim Sistemleri Dergisi, 1(3), 234245.

Krieber, M., Bartl-Pokorny, K. D., Pokorny, F. B., Zhang, D., Landerl, K., Körner, C., ... Marschik, P. B. (2017). Eye movements during silent and oral reading in a regular orthography: Basic characteristics and correlations with childhood cognitive abilities and adolescent reading skills. PloS one, 12(2), e0170986.

McMillan, J. H., \& Schumacher, S. (2014). Research in education: Evidence-based inquiry. Pearson Higher Ed.

Nelson, J. (2010). Reading skill and components of word knowledge affect eye movements during reading (PhD Thesis). University of Pittsburgh.

Onursoy, S., Kılıç, D., \& Er, F. (2010). Gazete okuma davranışı ve okuma yolu: Bir göz izleme çalışması.

Panel (US), N. R., Health, N. I. of C., \& Development (US), H. (2000). Report of the national reading panel: Teaching children to read: An evidence-based assessment of the scientific research literature on reading and its implications for reading instruction: Reports of the subgroups. National Institute of Child Health and Human Development, National Institutes of Health.

Rayner, K. (2009). Eye movements and attention in reading, scene perception, and visual search. The quarterly journal of experimental psychology, 62(8), 1457-1506.

Schooler, J. W. (2004). Zoning Out while Reading: Evidence for Dissociations between Experience and Metaconsciousness Jonathan W. Schooler, Erik D. Reichle, and David V. Halpern. Thinking and seeing: Visual metacognition in adults and children, 203. 
Solomon, M. J. (2009). Do readers access featural phonetic information when reading silently or out loud? An examination of the use of vowel length as a pre-phonemic featural property. State University of New York at Binghamton.

Ünalan, Ş. (2006). Türkçe öğretimi (3. Baskı), Nobel Yayın Dağıtım, Ankara. Türkçe Dersinde Bilişsel Farkındalık Okuma Stratejileri Öğretiminin Etkililiği.

Vadivel, K. S. (2014). Modeling Eye Tracking Data with Application to Object Detection. University of California, Santa Barbara.

Vorstius, C., Radach, R., \& Lonigan, C. J. (2014). Eye movements in developing readers: A comparison of silent and oral sentence reading. Visual Cognition, 3-4(22), 458-485.

Wallot, S. (2011). The role of reading fluency, text difficulty and prior knowledge in complex reading tasks (PhD Thesis). University of Cincinnati. 